\title{
On the Significance of English Classroom Discourse Corpus Construction
}

\author{
Dapeng WANG \\ Teaching and Research Institute of Foreign Languages \\ Bohai University \\ Jinzhou,Liaoning, 121013 China
}

\begin{abstract}
Classroom discourse can be a direct response to the quality and effectiveness of classroom teaching. The building of college English classroom discourse corpus can study the discourse relationship between teachers and students, classroom teaching effects and the problems that exist in teaching. According to classroom discourse study, this paper proposed suggestions on how to build classroom discourse and issues should be noted in the process of classroom discourse corpus building.
\end{abstract}

Keywords- Classroom discourse, corpus, meaning

\section{INTRODUCTION}

In recent years, in the field of corpus linguistics, many monographs, papers and other results related to corpus are constantly emerging, and the research achievement "corpusbased" which is relevant to language teaching and language learning is particularly eye-catching. Clearly, in the development of learners' dictionaries, corpus linguistics contributed a lot. Corpus also seems to be necessary resources to compilation of grammar books and textbooks. However, the widespread use of the term "corpus linguistics" does not mean its study results have been widely applied; on the contrary, its practical significance to language teaching has been ignored.

Recently, corpus of English classroom discourse has become an important part of applied linguistics research, on the one hand, it is reflected on English language acquisition research under real classroom, which aims to explore teacher talk, teaching behavior, interaction and questioning approach, providing English learners certain kind of language input and certain kind of language output, and explain the inner meaning of language acquisition through the phenomenon. On the other hand, it also embodies on the impact of classroom discourse corpus towards teacher training and professional development of teachers. Therefore, the need for research on the construction of classroom discourse corpus of English teaching is of great significance towards the teaching and study of secondary school teachers.

\section{DEFINITION AND FEATURES OF CLASSROOM DISCOURSE}

Classroom discourse is a very broad concept, including teacher talk, student talk, teacher-students interaction talk, and even classroom gossip. So classroom discourse is not only an important field of educational research, but also important areas of linguistics and second language acquisition. In the study of second language acquisition, classroom discourse (classroom talk) has three main pragmatic functions (Hall \& Walsh). First, classroom discourse is comprehensible language input and output as a stylistic code in second language acquisition, the code can better help learners to acquire real comprehensible language input, while at the same time, help learners to produce comprehensible output according to different real or fictitious discourse context. We can call this feature of language linguistic feature. Second, classroom discourse possesses the function of meaningful consultation, knowledge negotiation, language faculty development, such as raising questions, interaction. Third, classroom discourse has the function of classroom organization, management, regulation of second language classroom activities and language behavior. We can call this linguistic feature as classroom procedural and behavior regulative pragmatic feature. When study the first feature, people pay attention to the features of the amount of speed, pause, stress, and lexical, syntactic and textual aspects and the adjustments in classroom discourse as language input and language output. The study of the second feature, people pay more attention to the impact of the way of raising question, response, feedback and interaction between teacher and student of classroom discourse have on classroom negotiation, knowledge construction and language faculty development. The study of the third characteristic, people attaches great importance to structural features suggested by language communication environment, classroom organization, classroom activities and communicative behavior and so on.

\section{DEFINITION OF ENGLISH CLASSROOM DISCOURSE CORPUS}

Corpus is a very popular term at home and abroad in recent years. It can be a written form of a language naturally occurring and can also be a spoken form. So high school English classroom discourse corpus can be understood as a collection of multi-modal corpus of teachers and students in high school English class, which includes audio, video, text, etc. And analyze and study English teachers discourse, discourse patterns and other aspects through classroom record multi-dimensionally. English classroom discourse corpus construction discussed in this article will focus on collecting and arranging teacher talk and students' response 
pattern, and compare the discourse of teachers, thereby establishing a corpus about high school English classroom discourse.

\section{FEATURES OF ENGLISH CLASSROOM DISCOURSE CORPUS BUILDING}

\section{A. Small and special}

Different from the millions of words capacity of some large, universal corpus of English learners has, our English classroom discourse corpus is small and specialized, specialized in collecting the classroom discourse of English majors in normal institutes. Calculating 4000-5000 words a class, planning to collect 60 classes, and it is about 300,000 words.

\section{B. Localization}

Different from domain-wide character required by large corpora, our corpus is limited to collecting school English education majors classroom discourse. Because the collected corpus mainly is for school students' self-analysis and reflection, and for promoting the development of their teaching ability, the corpus should be easy to identify the source and the duration can be tracked. Of course, you should pay attention to the use the same format and annotation symbols transliteration of large corpora, so as to dock and share when conditions are ripe.

\section{Participation and diachronic}

Our process building the database is the process of English normal students' participation in the classroom discourse study, they will participate in classroom corpus collection, transcription and even labeling and analysis. In addition, we plan to complete gradually among the interns in several sessions, rather than one-off completion in a short term. It is the need for decentralizing labor intensity (recording transliteration is labor-intensive work); on the other hand, it is necessary for the diachronic study. We will examine whether the classroom discourse behavior of normal students would change over time or change by the environment, particularly to check whether it will change by the application of classroom discourse.

\section{THE RESEARCH STATUS OF CORPUS AND THE PRINCIPLE OF CORPUS CONSTRUCTION}

In our country, studies on the scientific system of corpus are from the late 1950s and early 1960s. The experience of constructing written corpora has been very mature, but building spoken English corpora, especially foreign language classroom discourse corpora are still in its infancy. At present, targeted at teacher teaching language output, the construction of classroom teaching corpus has not attracted enough Chinese scholars' attention. In fact, the exploitation of oral language or classroom discourse corpus in other countries in the world is also extremely limited. International corpus linguist Kennedy pointed out that spoken corpus truly reflects the essence of a language directly, and because of the expensive development costs, the research value is very precious. At present, targeted at teacher teaching language output, the construction of classroom teaching corpus has not attracted enough Chinese scholars' attention. Therefore, making full use of computer corpus linguistics research methods, to construct college English classroom discourse spoken corpus, can fully and truly know the situation in today's classroom and explore the characteristics of college English classroom discourse, the impact of language output of university English language teachers on students' output, the differences and the characteristics of classroom discourse, and educational idea of teachers so as to improve college English teaching level.

The construction process of English classroom discourse corpus can include preparation, data collection, text transcription, corpus annotation and initial generation of corpus. Preparation includes literature study, tool design, sample selection and a pilot study. It is necessary to conduct a pilot study before making a large-scale corpus collection. It can test the rationality of a questionnaire, and the feasibility of corpus annotation. First, the sample of the corpus should be representative. The greater the capacity of the corpus is, the more representative the corpus is. Empirical studies show that 100,000 word corpus can meet the needs of phonological studies. 500,000 to 1 million word corpus can meet the research needs of syntax. Second, the collected corpus should cover all aspects of English teaching, including teachers' age, gender, education, ethnicity, status, in which grade they are, the school's educational level, the nature of the school and so on. Third, in order to ensure the comparability of the corpus, classroom discourse collection should be subject to periods in each unit. Fourth, classroom teachers selected should have a certain proportion, including the proportion of male and female teachers, high, medium and low grade teacher's proportion etc.

\section{THE PRACTICAL APPLICATION OF CORPUS LINGUISTICS}

The practical application of corpus linguistics can be shown in four main aspects: Firstly, it's lexicography. Large corpus is highly useful for lexicography. For example, "Collins-Belt English Dictionary" has its own large corpus. "Longman English Dictionary" is based on the Longman Corpus Network which consists of three sub-corpus: First, it's Longman-Lancaster Corpus, containing 30 million written words appearing in various English books; Second, it's Longman students' Corpus, which is the only one that has written English corpus of English learners from each countries; Third, it's English II corpus, containing the first daily dialogue corpus; What's more, the search function and statistical methods of corpus provide convenience to syntactic research, discourse analysis, conversation analysis and speech research. I-CAME on the Internet introduces many corpus-based language research projects in recent years, which shows that corpus is of great significance for language research. Corpus linguistics can handle corpus in a certain range, revealing the history of the language in a certain stage; thirdly, corpus linguistics has a direct impact on language teaching and foreign language teaching. Corpus, as a source of many real language data, has been widely used 
in teaching in recent years. Native language acquisition and foreign language learning can not work without the corpus study. Corpus also plays an important role in language teaching of other languages as special purposes, such as journalistic language, scientific and cultural language. Fourthly, Corpus Translation Studies was a whole new mode of translation studies, which appears in the 1990s. Parallel corpus and comparable corpus are suitable for translation studies. The outstanding achievements made in corpus translation studies are the study of translation universals, simplification existed in translation, the verification at a certain extent of the assumptions about general characteristics of clarification and standardization in corpus translation studies.

Since corpus is powerful in statistics etc, it is also widely used in other areas, such as the comparative study of second language and written language based on second language corpus data, the features of chunks using in discourse vocabulary, grammar and conversation discourse, description of the structure of discourse, the study of translation between English and Chinese and language test by the use of parallel corpus and so on.

\section{THE NECESSITY OF BUILDING ENGLISH CLASSROOM DISCOURSE CORPUS}

\section{A. The influence of corpus linguistics on phonetic teaching}

The development of computer technology makes it possible to use corpus to present discourse and its video, and also provides a convenient condition for the application of corpus in phonetic teaching. Materials used in traditional phonetic teaching have a big difference in the usage of pronunciation and intonation in reality, which is considered as the reason why phonetic teaching is not only boring but also difficult to carry out. Now the standard and reliable corpus offers a lot of fresh instances for phonetic teaching, so that foreign language teachers and students can sum up the rules with the help of corpus in order to carry out phonetic teaching activities better.

\section{B. Corpus Linguistics' affect on vocabulary teaching}

In the area of corpus resource, vocabulary teaching is one of the first fields used in foreign language teaching. The practicality of Corpus applied to vocabulary teaching is mainly reflected in: Through a lot of real language examples to learn words and phrases, understand the meaning and basic usage of a word or phrase; help students distinguish synonyms, synonyms; help students master word order and syntactic structure.

\section{Corpus linguistics impact on aspects of grammar teaching}

The traditional model of grammar teaching systems rely mainly on teachers' systematically explanation of grammar rules and students' repeated drill, and the principle of corpus linguistics applied in grammar teaching is to enable students contact with a large number of real, meaningful corpora and to actively discover and induce the basic features of language form and the usage law.

\section{The impact of corpus linguistics on teaching of reading}

The monotony of classroom reading teaching tends to make the classroom atmosphere become dull, boring and lifeless. However, the application of the corpus in the teaching of reading can combine spoken language, text and audio-visual and that will make classroom teaching intuitive and image. Through online search of the corpus, classroom teachers can collect the Anglo-American fiction, essays, speeches word, screenplays, press releases, papers, textbooks and other real natural corpus, and some even comes with audio and video data. Display the reading teaching materials from video, audio, text corpus, letting students observe, perceive, analyze, compare, deductive and inductive, thus completing the accumulation of reading amount and cultivation and improvement of reading skills.

\section{CONCLUSION}

The value of corpus linguistics to foreign language teaching is evident; corpus resource use can change our understanding of the existing teaching resources and patterns radically. Especially for those schools which is in remote areas, lack of teaching resources. Corpus resources can quickly and effectively enhance the ability of foreign language teaching there, and to improve the quality of foreign language teaching. Also, high school classroom discourse corpus provides a very important study and research material for English teachers. I believe that, with the continuous construction and expansion of high school English classroom discourse corpus, which will play a greater role on high school English teachers, researchers and students of elementary English education.

\section{REFERENCES}

[1] Nongyunduan. Corpus Corpus Linguistics and Zhuang construction [J]. Exams Weekly, 2011, 60:34-36.

[2] Zhao xiaoying, Yin Yao. corpus studies classroom value - Review. "From Corpus to Classroom: language use and language teaching" [J] foreign language, 2009, 03:88-92.

[3] Maxiao Huan. Study Impact corpus linguistics in Classroom Teaching [J]. Yichun College, 2010, 07:170-172.

[4] Zhang Huiping, Yong-Bing Liu. Corpus-based high school English teacher classroom discourse markers study [J]. Foreign Language Teaching and Research, 2010, 05:356 -363 to +400 .

[5] Shi Caining, Wang Haoqing. Role of Corpus Linguistics for Foreign Language Teaching [J]. Yangling Vocational and Technical College, 2007,01:73-75.

[6] Liu Hui, Li Yanhui. On the necessity of primary and secondary school English classroom discourse corpus construction [J]. Chinese school education, 2012,31:89.

[7] Liu Hui, Ma Huiying English Corpus Review of classroom discourse. [J]. Tianjin Normal University (Elementary Education Edition),2013,03:46-48.

[8] Lijia, Han Huizhong,Li Kaiyun. College English Corpus Construction of Classroom Discourse [J]. Ideological front, 2011, S1 :386-387. 